\title{
Cryptosporidiosis in Iranian Farm Workers and Their Household Members: A Hypothesis about Possible Zoonotic Transmission
}

\author{
Morteza Izadi, ${ }^{1}$ Nematollah Jonaidi-Jafari, ${ }^{1}$ Amin Saburi, ${ }^{2}$ Hossein Eyni, ${ }^{3}$ \\ Mohammad-Reza Rezaiemanesh, ${ }^{1}$ and Reza Ranjbar ${ }^{4}$ \\ ${ }^{1}$ Health Research Center, Baqiyatallah University of Medical Sciences, Mollasadra Street, Vanak Square, Tehran 14359151371, Iran \\ ${ }^{2}$ Chemical Injuries Research Center, Baqiyatallah University of Medical Sciences, Tehran 14359151371, Iran \\ ${ }^{3}$ Isfahan University of Medical Sciences, Isfahan, Iran \\ ${ }^{4}$ Molecular Biology Research Center, Baqiyatallah University of Medical Sciences, Tehran 14359151371, Iran
}

Correspondence should be addressed to Nematollah Jonaidi-Jafari; jonaidi2000@yahoo.com

Received 27 December 2013; Accepted 18 February 2014; Published 27 April 2014

Academic Editor: Luis E. Cuevas

Copyright (c) 2014 Morteza Izadi et al. This is an open access article distributed under the Creative Commons Attribution License, which permits unrestricted use, distribution, and reproduction in any medium, provided the original work is properly cited.

Objectives. The prevalence of Cryptosporidium and the risk factors of zoonotic transmission in Najafabad, Isfahan, Iran dairy farms were examined. Methods. One fecal sample was collected from all calves less than 6 months old in eight dairy farms around Najafabad (Isfahan province, Central Iran) as well as individuals working in these farms and their household members. A twostep nested PCR protocol was used to amplify the $18 \mathrm{~S}$ rRNA gene $(830 \mathrm{bp})$. Results. Cryptosporidium was identified in the stool of 36 (prevalence 8.5\%) of 96 farm workers and 326 household members. Furthermore, 31 (14.2\%) of 218 calf samples were positive. Cryptosporidium parvum was identified in $15(72 \%)$ of the positive farm workers and $10(65 \%)$ of the positive household members. Of the positive calves, 20 (64.5\%) were infected with C. parvum, indicating possible zoonotic transmission in these farms. Contact with calves $(P<0.0001)$ was the most significant risk factor of $C$. parvum infection. A considerable negative association was observed between $C$. parvum infection and cleaning of shoes/boots after daily work $(P=0.004)$, hand washing $(P=0.013)$, and use of piped water $(P<0.006)$. In the multivariate analysis with logistic regression, only contact with calves was significant. Conclusion. Zoonotic transmission of $C$. parvum due to contact with calves is predominant among farm workers and their household members of this region and appropriate health measures must be applied to control the infection and decrease of zoonotic transmission of this parasite.

\section{Introduction}

Cryptosporidium species are apicomplexan protozoa that infect humans and a wide variety of vertebrate animals. Cryptosporidiosis is a self-limiting disease of intestinal tract in immune-competent individuals and a severe chronic disease in immunocompromised patients [1]. Cryptosporidiosis has been considered to be a zoonotic disease and therefore is of potential significance from both disease and public health prospective. Transmission of Cryptosporidium spp. from farm animals to humans has been documented in accidental infection of veterinary workers $[2,3]$. Cattle have been considered as a substantial source of zoonotic cryptosporidiosis. Young animals appear to be more susceptible to infection and disease, while infections in adults are often asymptomatic or do not occur [4]. Among cattle, calves are prone to infection immediately after birth and continue so for several months [5]. Contact with infected calves has been implicated as the reason of many small cryptosporidiosis outbreaks in humans $[6,7]$.

Therefore a cross-sectional study was performed to determine the occurrence and prevalence of infection in farm workers and their household members as well as calves to estimate the risk of zoonotic transmission and survey potential risk factors of infection with Cryptosporidium zoonotic species. 
TABLE 1: Prevalence of Cryptosporidium species in calves.

\begin{tabular}{lccccccccc}
\hline \multirow{2}{*}{ Age } & \multirow{2}{*}{$n$} & \multicolumn{2}{c}{ Cryptosporidium } & \multicolumn{2}{c}{ C.parvum } & \multicolumn{2}{c}{ C.bovis } & \multicolumn{2}{c}{ C.ryanae } \\
& & Pos. & Prevalence (\%) & Pos. & Prevalence (\%) & Pos. & Prevalence (\%) & Pos. & Prevalence (\%) \\
\hline Preweaned & 94 & 20 & 21 & 18 & 90 & 2 & 10 & 0 & 0 \\
Postweaned & 124 & 11 & 9 & 0 & 0 & 7 & 60 & 4 & 40 \\
\hline Total & 218 & 31 & 14 & 20 & 62.5 & 9 & 25 & 4 & 12.5 \\
\hline
\end{tabular}

\section{Materials and Methods}

2.1. Sampling and Specimen Processing. One fecal sample was collected from all calves less than 6 months old in 8 dairy farms around Najafabad (Isfahan province, Central Iran) as well as individuals working in these farms and their household members. From September 2009 to March 2010, 218 and 422 fecal samples were collected from calves and humans, respectively. All farm workers and their families agreed to cooperate in this study. Each specimen was placed in a plastic vial, brought immediately to laboratory, and stored at $4^{\circ} \mathrm{C}$ until analysis.

Age and sex, number of household members, contact with calves, and source of drinking water, hand washing after defecation and daily work, and cleaning shoes/boots after daily works were recorded. The fecal specimens were classified according to their consistency as diarrheic or nondiarrheic.

The fecal specimens were concentrated using a sucrose solution with a specific gravity of 1.200 at a centrifuge speed of $800 \times \mathrm{g}$ for 10 minutes. All of the samples were stained by the modified Ziehl-Neelsen method [8] and examined under bright field microscopy. A sample considered Cryptosporidium positive if typical oocysts $4-6 \mu \mathrm{m}$ in diameter were visible.

2.2. DNA Extraction. Microscopically positive fecal samples were subjected to six cycles of freeze-thaw in liquid nitrogen and a $95^{\circ} \mathrm{C}$ water bath to rupture the oocysts. DNA was isolated from aliquots of frozen stool using the QIAamp DNA stool minikit (QIAGEN, USA) according to the manufacturer's instructions.

2.3. $18 S$ rDNA Gene Amplification and Sequencing. A twostep nested PCR protocol was used to amplify the $18 \mathrm{~S}$ rRNA gene ( $830 \mathrm{bp})$. The fragment of the $18 \mathrm{~S}$ rRNA gene was amplified by PCR using the following primers previously described by Xiao et al. [9]: 5-TTCTAGAGCTAATACATGCG-3 and 5-CCCATTTCCTTCGAAACAGGA-3 for primary PCR and 5-GGAAGGGTTGTATTTATTAGATAAAG-3 and 5AAGGAGTAAGGAACAACCTCCA-3 for secondary PCR. For the primary PCR step, PCR mixture contained 1x PCR buffer, $3 \mathrm{mM} \mathrm{MgCl}_{2}, 0.2 \mathrm{mM}$ of each dNTP, $2.5 \mathrm{U}$ Taq, $2.5 \mu \mathrm{L}$ of BSA $(0.1 \mathrm{~g} / 10 \mathrm{~mL})$, for each forward and reverse primer in a total of $50 \mu \mathrm{L}$ reaction volume. A total of 35 cycles, each consisting of $94^{\circ} \mathrm{C}$ for $45 \mathrm{~s}, 59^{\circ} \mathrm{C}$ for $45 \mathrm{~s}$, and $72^{\circ} \mathrm{C}$ for $1 \mathrm{~min}$, were performed; an initial hot start at $94^{\circ} \mathrm{C}$ for $3 \mathrm{~min}$ and a final extension step at $72^{\circ} \mathrm{C}$ for $7 \mathrm{~min}$ were also included. For the secondary PCR step, the PCR mixture was identical except that a concentration of $1.5 \mathrm{mM} \mathrm{MgCl}_{2}$ was used. A total of 40 cycles, each consisting of $94^{\circ} \mathrm{C}$ for $30 \mathrm{~s}, 58^{\circ} \mathrm{C}$ for $90 \mathrm{~s}$, and $72^{\circ} \mathrm{C}$ for $2 \mathrm{~min}$, were performed; an initial hot start at $94^{\circ} \mathrm{C}$ for $3 \mathrm{~min}$ and a final extension step at $72^{\circ} \mathrm{C}$ for $7 \mathrm{~min}$ were also included. PCR products were analyzed on $1 \%$ agarose gel and visualized by ethidium bromide staining.

PCR products were purified and sequenced subsequently using the terminator V3.1 cycle sequencing kit (Applied Biosystems). Sequences were assembled using the program SeqMan (DNASTAR, USA).

2.4. Statistical Analysis. The prevalence of Cryptosporidium infection and prevalence of Cryptosporidium species in preweaned calves were compared with postweaned calves as well as humans. Determination of the association between infection and age, sex, and fecal consistency was performed using chi-square or Fisher's exact test. Results were considered to be significant at $P<0.05$.

Farmers were asked to complete a questionnaire on potential risk factors for Cryptosporidium infection including age, sex, contact with calves, cleaning shoes/boots after daily work, hand washing after work, and contact with soil and use of piped water as their water source.

A univariate analysis for the relation between Cryptosporidium infection and potential risk factors was performed (odds ratio) and the significance of variable association was tested using Wald's test. To appraise efficiently the association between exposure and consequence and to assess the effect of possible confounding variables, a multivariate analysis was performed by means of a logistic regression model. Only variables that showed Wald's $P$ value smaller than 0.05 were included in the multivariate model and a backward deletion process was then performed. Analysis was carried out using computer software SPSS ver.12 (SPSS Inc., USA). In both the univariate and multivariate analyses, associations were considered significant at $P<0.05$.

\section{Results}

Two hundred and eighteen calf samples were examined and a prevalence of $14.2 \%(31 / 218)$ was found. 20 (21\%) of positive samples were detected in preweaned calves, while only 11 $(9 \%)$ of positive cases were observed in postweaned calves $(P<0.05)$ (Table 1$)$. The highest prevalence was observed in calves with approximately 2 weeks of age (Figure 1). 19 (68\%) Cryptosporidium positive calves were diarrheic while 12 (32\%) were nondiarrheic $(P<0.02)$ (Table 2$)$.

Of 422 humans sampled, 110 were farm workers and 312 were household members. Although farm workers were 
TABLE 2: Cryptosporidum prevalence in diarrheic and nondiarrheic calves and humans.

\begin{tabular}{lcccc}
\hline Host & Cryptosporidium & Sample number & Diarrheic* (\%) & Nondiarrheic (\%) \\
\hline \multirow{2}{*}{ Calve } & Pos. & 31 & $19(68)$ & $12(32)$ \\
& Neg. & 187 & $13(7)$ & $174(93)$ \\
\multirow{2}{*}{ Human } & Pos. & 36 & $9(25)$ & $27(75)$ \\
& Neg. & 386 & $31(8)$ & $355(92)$ \\
\hline
\end{tabular}

${ }^{*}$ Diarrhea was defined as having $\geq 1$ day with $>3$ liquid or semiliquid stools.

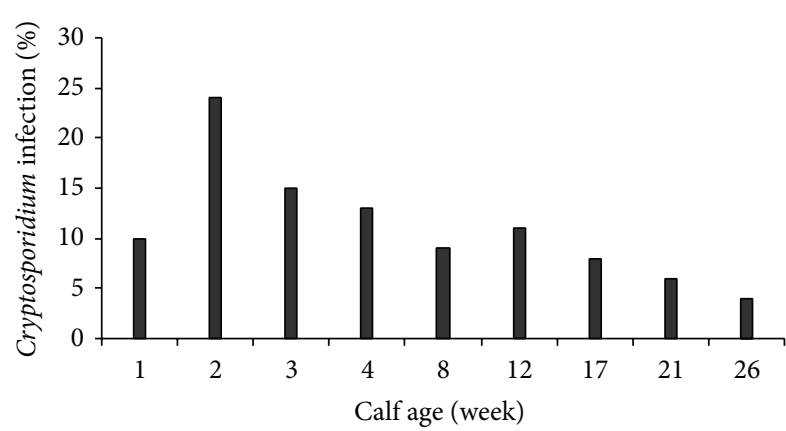

FIGURE 1: Distribution of Cryptosporidium infection in various age groups of calves.

two times more likely to be infected, the prevalence of Cryptosporidium infection was not significantly higher in the former $(P<0.105)$. All 627 samples from calves and humans of known fecal consistency were used to determine relationship between Cryptosporidium infection and diarrhea (Table 2).

Total prevalence of Cryptosporidium infection in humans was $8.5 \%(63 / 422)$. The infection rate in $<5$-year-old group and in $>5$-year-old group was $7(9.6 \%)$ and $29(8.3 \%)$, respectively (Table 3 ). All positive samples were genotyped. Cryptosporidium parvum was the most common genotype identified in $64.6 \%$ calves $(20 / 31)$, followed by Cryptosporidium bovis in 29\% (9/31) and Cryptosporidium ryanae (previously identified as the Cryptosporidium deer-like genotype) in $6.4 \%(2 / 31)$ of the calves (Table 1$)$. In preweaned calves Cryptosporidium parvum and Cryptosporidium bovis were responsible for $18(90 \%)$ and $2(10 \%)$ of infections, respectively. In postweaned calves no Cryptosporidium parvum was detected, while Cryptosporidium bovis and Cryptosporidium ryanae were present in $7(60 \%)$ and $4(40 \%)$ of infections, respectively (Table 1). The results of Cryptosporidium and Cryptosporidium species prevalence of infection in various locations and herds, based on age and using 18s rRNA amplification and sequencing, were shown in Table 4.

Only 36/63 (57\%) microscopy-positive human samples were sequenced. In thirty-six positive human samples Cryptosporidium parvum was identified in 28 (78\%) samples and Cryptosporidium hominis in 8 (22\%) samples (Table 3). 19 (68\%) of the Cryptosporidium-positive calf samples were diarrheic, while only 13 (7\%) of the Cryptosporidium-negative samples were diarrheic $(P<0.002)$. In humans, $9(25 \%)$ of the positive samples were diarrheic while $27(75 \%)$ of the negative samples were found to be diarrheic $(P<0.03)$.
Thus, it was obvious that Cryptosporidium infection appears to be associated with the occurrence of diarrhea in calves and humans.

The results of the univariate analysis are shown in Table 5. In humans, Cryptosporidium parvum infection was not associated with age less than 5 years $(\mathrm{OR}=1.65 ; 95 \% \mathrm{CI}=0.67$ $4.05 ; P=0.265)$, contact with soil $(\mathrm{OR}=1.3 ; 95 \% \mathrm{CI}=0.57$ $2.97 ; P=0.527)$, diarrhea $(\mathrm{OR}=1.65 ; 95 \% \mathrm{CI}=0.54-5.04$; $P=0.369)$, and crowding ( $\mathrm{OR}=2.06 ; 95 \% \mathrm{CI}=0.81-5.21$; $P=0.117)$. A significant association was found with contact with calves $(\mathrm{OR}=6.68 ; 95 \% \mathrm{CI}=1.99-22.39 ; P<0.0001)$. Sex was not correlated with Cryptosporidium parvum infection $(\mathrm{OR}=1.06 ; 95 \% \mathrm{CI}=0.49-2.3 ; P=0.877)$.

Cleaning of shoes/boots after daily work $(\mathrm{OR}=0.33 ; 95 \%$ $\mathrm{CI}=0.15-0.73 ; P<0.004)$, use of piped water $(\mathrm{OR}=0.34$; 95\% CI $=0.15-0.75 ; P<0.006)$, and hand washing after daily work and defecation $(\mathrm{OR}=0.38 ; 95 \% \mathrm{CI}=0.17-0.83$; $P<0.013$ ) were protective factors against Cryptosporidium parvum infection.

In multivariate analysis with a backward deletion process, the nonsignificant factors were excluded from the model. In the final analysis only contact with calves maintained a significant association with infection (Table 6).

\section{Discussion}

In this study we examined fecal samples of calves and farm workers and their household members to determine the prevalence of Cryptosporidium infection and Cryptosporidium species in calves and humans to assess zoonotic transmission possibility between calves and humans.

Several studies evaluated the prevalence of Cryptosporidium infection in bovine and humans in Iran [10-12]. In our study the prevalence of Cryptosporidium infection was $14.2 \%(31 / 218)$ and $8.5 \%(36 / 422)$ in calves and humans, respectively. Azami et al. found 6.2\% (30/480) prevalence of infection in calves and cattle in Isfahan [10]. The higher prevalence in this study also in Isfahan may be due to the use of highly sensitive 18s rRNA gene amplification. Moreover, the cattle ages might have been different with younger ones being more likely to be infected. Also, the target population which was studied in two studies was different (children and immunocompromized patients versus normal adults). Previously, prevalence was reported to be $12 \%$ (35/292), $17.7 \%$ $(19 / 107), 18.8 \%(51 / 275)$, and $6.4 \%(31 / 482)$ in calves of various regions of Iran, respectively [11-14]. An infection rate of $19.5 \%$ of C. parvum among 174 preweaned calves was significantly higher than the $3.1 \%$ among 98 postweaned 
TABle 3: Prevalence of Cryptosporidium and Cryptosporidium genotypes in the farm workers and their household members based on age.

\begin{tabular}{|c|c|c|c|c|c|c|c|}
\hline \multirow{2}{*}{ Age } & \multirow{2}{*}{$n$} & \multicolumn{2}{|c|}{ Cryptosporidium } & \multicolumn{2}{|c|}{ C.parvum } & \multicolumn{2}{|c|}{ C.hominis } \\
\hline & & Pos & Prevalence (\%) & Pos. & Prevalence (\%) & Pos. & Prevalence (\%) \\
\hline$<5$ years & 73 & 7 & 9.6 & 7 & 100 & 0 & 0 \\
\hline$>5$ years & 349 & 29 & 8.3 & 21 & 72.4 & 8 & 27.6 \\
\hline Total & 422 & 36 & 8.5 & 28 & 78 & 8 & 22 \\
\hline
\end{tabular}

TABLE 4: Prevalence of Cryptosporidium and Cryptosporidium genotypes in the calves based on age.

\begin{tabular}{|c|c|c|c|c|c|c|c|c|c|c|c|}
\hline \multirow{2}{*}{ Location } & \multirow{2}{*}{ Herd } & \multirow{2}{*}{ Age } & \multirow{2}{*}{$n$} & \multicolumn{2}{|c|}{ Cryptosporidium } & \multicolumn{2}{|c|}{ C.parvum } & \multicolumn{2}{|c|}{ C.bovis } & \multicolumn{2}{|c|}{ C.ryanae } \\
\hline & & & & Pos. & Prevalence (\%) & Pos. & Prevalence (\%) & Pos. & Prevalence (\%) & Pos. & Prevalence (\%) \\
\hline \multirow{4}{*}{ Goldasht } & \multirow{2}{*}{ G1 } & $<2$ months & 25 & 3 & 12 & 3 & 100 & 0 & 0 & 0 & 0 \\
\hline & & $2-6$ months & 14 & 1 & 7.1 & 0 & 0 & 1 & 100 & 0 & 0 \\
\hline & \multirow{2}{*}{ G2 } & $<2$ months & 22 & 3 & 13.6 & 2 & 9.1 & 1 & 4.5 & 0 & 0 \\
\hline & & 2-6 months & 15 & 2 & 13.3 & 0 & 0 & 2 & 100 & 0 & 0 \\
\hline \multirow{3}{*}{ Juzdan } & \multirow{2}{*}{ J1 } & $<2$ months & 13 & 2 & 15.4 & 2 & 100 & 0 & 0 & 0 & 0 \\
\hline & & 2-6 months & 7 & 0 & 0 & 0 & 0 & 0 & 0 & 0 & 0 \\
\hline & $\mathrm{J} 2$ & 2-6 months & 14 & 3 & 21.4 & 0 & 0 & 2 & 14.3 & 1 & 7.1 \\
\hline \multirow{3}{*}{ Dehegh } & \multirow{2}{*}{ D1 } & $<2$ months & 11 & 2 & 18.1 & 2 & 100 & 0 & 0 & 0 & 0 \\
\hline & & $2-6$ months & 9 & 1 & 11.1 & 0 & 0 & 1 & 100 & 0 & 0 \\
\hline & D2 & $<2$ months & 13 & 2 & 15.4 & 2 & 100 & 0 & 0 & 0 & 0 \\
\hline \multirow{4}{*}{ Alvijeh } & \multirow{2}{*}{ O1 } & $<2$ months & 33 & 8 & 24.2 & 7 & 21.2 & 1 & 3 & 0 & 0 \\
\hline & & $2-6$ months & 17 & 2 & 11.8 & 0 & 0 & 1 & 5.9 & 1 & 5.9 \\
\hline & \multirow{2}{*}{$\mathrm{O} 2$} & $<2$ months & 14 & 2 & 14.3 & 2 & 100 & 0 & 0 & 0 & 0 \\
\hline & & 2-6 months & 11 & 0 & 0 & 0 & 0 & 0 & 0 & 0 & 0 \\
\hline Total & & & 218 & 31 & 14.2 & 20 & 9.2 & 9 & 4.1 & 2 & 0.9 \\
\hline
\end{tabular}

calves $(P<0.0006)[13]$. Similar results have been observed in calves in point prevalence studies worldwide [15-19]. The highest prevalence was found in calves by two weeks of age $(24 \%)$ which is consistent with reports from countries throughout the world $[15,19,20]$. Molecular characterization of Cryptosporidium using 18s rRNA genes indicated the presence of C. parvum, C. bovis, and C. ryanae in agreement with other point prevalence studies of calves [21-23]. In the present study, C. parvum was responsible for $64.5 \%$ while C. bovis and C. ryanae were identified in $29 \%$ and $6.5 \%$ of infections of calves, respectively. The most prevalent genotype in preweaned calves was C. parvum (91\%) followed by C. bovis (9\%). Otherwise in postweaned calves most infections were due to C. bovis (78\%), C. ryanae was responsible for $22 \%$ of infections, and no animal with positive C. parvum specimen was observed in this group. It had been reported that cattle are commonly infected with three other Cryptosporidium spp. in addition to C. parvum, including C. bovis, C. ryanae (previously known as Cryptosporidium deer-like genotype), and $C$. andersoni. Numerous recent studies in various areas indicated the existence of an age-related occurrence of Cryptosporidium spp. In dairy cattle, C. parvum is mostly found in preweaned calves, $C$. bovis and C. ryanae in postweaned calves, and $C$. andersoni in yearling and adult cattle [21, 24-27]. Thus, in cattle, only preweaned calves are major source of C. parvum (one of the most prevalent zoonotic genotypes) [28].
In 36 PCR-positive human samples C. parvum was identified in 28 samples (78\%) and C. hominis (nonzoonotic genotype) in 8 samples (22\%). As shown earlier, the distribution of C. parvum and C. hominis in humans differs in different geographic regions. In European countries, both C. parvum and C. hominis are common in humans $[29,30]$. In the Middle East especially in Iran, C. parvum is the dominant species in humans [11, 31-33]. In the rest of the world, C. hominis is usually the predominant species in humans [34-36]. C. parvum was identified in $72 \%$ of the positive farm workers and in $65 \%$ of the household members. These results are consistent with Siwila et al.s study in Zambia that found $C$. parvum in $75 \%$ of positive farm workers and $60 \%$ of the household members [37]. All seven positive samples from less than 5-year-old children were identified as C. parvum, while in twenty-nine positive samples of more than 5-yearold individuals, 21 samples $(72.4 \%)$ were C. parvum and 8 samples (27.4\%) were C. hominis.

There are age-association variations in the disease burden between C. parvum and C. hominis [29]. In Iran, Kuwait, and Turkey almost all cryptosporidiosis cases in children are caused by C. parvum, while in The Netherlands and UK C. hominis was more commonly found in children [29, 38]. This study is the first survey of C. parvum potential risk factors in Iranian farm workers and their household members. We found significant association between contact 
TABLE 5: Univariate analysis of association between potential risk factors and Cryptosporidium parvum infection in farm workers and their household members.

\begin{tabular}{|c|c|c|c|c|}
\hline Risk factors & Odds ratio & $95 \% \mathrm{CI}$ & $\chi^{2}$ & $P$ value \\
\hline Age $^{a}$ & 1.65 & $0.67-4.05$ & 1.24 & 0.265 \\
\hline $\operatorname{Sex}^{\mathrm{b}}$ & 1.06 & $0.49-2.30$ & 0.24 & 0.877 \\
\hline Crowding $^{c}$ & 2.06 & $0.81-5.21$ & 2.45 & $<0.117$ \\
\hline Diarrhea & 1.65 & $0.54-5.04$ & 0.8 & $<0.369$ \\
\hline Contact with calves & 6.68 & $1.99-22.39$ & 12.31 & 0.0001 \\
\hline Cleaning of shoes/boots & 0.33 & $0.15-0.73$ & 8.1 & $<0.004$ \\
\hline Hand washing after daily work and defecation & 0.38 & $0.17-083$ & 6.20 & $<0.013$ \\
\hline Use of piped water & 0.34 & $0.15-0.75$ & 7.55 & 0.006 \\
\hline
\end{tabular}

${ }^{a}<5$ years versus $>5$ years old.

${ }^{\mathrm{b}}$ Male versus female.

${ }^{c}$ Crowding is defined as families with more than 4 members.

TABLE 6: Final model of multivariate analysis of Cryptosporidium parvum infection risk factors.

\begin{tabular}{lccccc}
\hline Risk factor & Odds ratio & $95 \%$ CI & Regression coefficient & SE & $P$ value \\
\hline Contact with calves & 8.3 & $2.3-26.5$ & 2.1 & 0.5 & 0.0000 \\
\hline
\end{tabular}

with calves and $C$. parvum infection $(\mathrm{OR}=6.68 ; 95 \% \mathrm{CI}=$ 1.99-22.39; $P<0.0001)$. Robertson et al. reported calf contact away from home as the risk factor of $C$. parvum infection in Melbourne $(\mathrm{OR}=2.9 ; 95 \% \mathrm{CI}=1.5-5.7)$ and Adelaide $(\mathrm{OR}=5.1 ; 95 \% \mathrm{CI}=1.5-17.3)$ [39]. Roy et al. reported contact with calves or cows $(\mathrm{OR}=3.5 ; 95 \% \mathrm{CI}=$ 1.8-6.8; $P<0.01)$ as risk factor in USA [40]. Hunter et al. identified touching cattle $(\mathrm{OR}=3.9 ; 95 \% \mathrm{CI}=1.4-10.0)$ as risk factor of infection in Wales and New England [41]. There is no significant association between age, sex, crowding, diarrhea, and contact with soil and C. parvum infection. But there was significant negative association between cleaning of shoes/boots after daily work, hand washing after work and defecation, and use of piped water and C. parvum infection. In other words these factors were potentially protective against C. parvum infection. In multivariate analysis, all risk factors for $C$. parvum infection were excluded except contact with calves. In this study contact with calves was the most important risk factor of C. parvum infection of farm workers and their household members, both in univariate and multivariate analyses. Cattle have been considered to be an important source of zoonotic cryptosporidiosis since the 1980s. It seems that the most important cause of many small cryptosporidiosis outbreaks in veterinary students and veterinarians, research technicians, and children attending agricultural camps and fairs is contact with infected calves [42-44]. But nowadays, there are many reports of different types of Cryptosporidium infections in different parts of the world every day which supports a powerful and efficient transmission [45].

The finding that $75 \%$ of the Cryptosporidium-positive humans were asymptomatic (nondiarrhoeic) is surprising and noteworthy. It is worth discussing this as it probably represents a further risk factor for transmission especially if this was shown to be in young children from which transmission is likely to occur. Although prevalence of asymptomatic careers in this study was reported as high as $75 \%$, this range may be variable by species of Cryptosporidium, the general health condition of human host for example being immunocompromised such as HIV positive and kidney transplant patients, the prevalence of positive calves and animal and previous outbreaks in that geographical region [46-49].

\section{Conclusion}

The results of present study clearly show that humans working close to calves are more likely to be at risk of zoonotic infection with C. parvum. As reported earlier, the clear predominance of C. parvum in Iranian people might consider the result of zoonotic transmission [31]. However, more comprehensive studies in Cryptosporidium spp. are needed to clarify accurately the zoonotic transmission of Cryptosporidium zoonotic genotypes. Particularly, further subtyping of $C$. parvum in humans and animals is needed to improve our knowledge of routes of transmission and potential risk factors in this region and other locations of Iran.

\section{Conflict of Interests}

There is no conflict of interests to state.

\section{Acknowledgments}

This study was supported financially by the Health Research Center, Baqiyatallah Medical University. The authors are grateful to farm workers and their household members, lab staff, and each of the subjects who generously participated in this study.

\section{References}

[1] R. M. Chalmers and A. P. Davies, "Minireview: clinical cryptosporidiosis," Experimental Parasitology, vol. 124, no. 1, pp.138$146,2010$. 
[2] G. Nichols, "Epidemiology," in Cryptosporidium and Cryptosporidiosis, R. Fayer and L. Xiao, Eds., pp. 79-118, CRC Press, Boca Raton, Fla, USA, 2nd edition, 2008.

[3] N. C. Reese, W. L. Current, J. V. Ernst, and W. S. Bailey, "Cryptosporidiosis of man and calf: a case report and results of experimental infections in mice and rats," American Journal of Tropical Medicine and Hygiene, vol. 31, no. 2, pp. 226-229, 1982.

[4] P. J. O'Donoghue, "Cryptosporidium and cryptosporidiosis in man and animals," International Journal for Parasitology, vol. 25, no. 2, pp. 139-195, 1995.

[5] L. Xiao and R. P. Herd, "Infection patterns of Cryptosporidium and Giardia in calves," Veterinary Parasitology, vol. 55, no. 3, pp. 257-262, 1994.

[6] K. E. Smith, S. A. Stenzel, J. B. Bender et al., "Outbreaks of enteric infections caused by multiple pathogens associated with calves at a farm day camp," Pediatric Infectious Disease Journal, vol. 23, no. 12, pp. 1098-1104, 2004.

[7] K. M. Kiang, J. M. Scheftel, F. T. Leano et al., "Recurrent outbreaks of cryptosporidiosis associated with calves among students at an educational farm programme, Minnesota, 2003," Epidemiology and Infection, vol. 134, no. 4, pp. 878-886, 2006.

[8] D. P. Casemore, M. Armstrong, and R. L. Sands, "Laboratory diagnosis of cryptosporidiosis," Journal of Clinical Pathology, vol. 38, no. 12, pp. 1337-1341, 1985.

[9] L. Xiao, L. Escalante, C. Yang et al., "Phylogenetic analysis of Cryptosporidium parasites based on the small subunit rRNA gene lucus," Applied and Environmental Microbiology, vol. 65, no. 4, pp. 1578-1583, 1999.

[10] M. Azami, D. D. Moghaddam, R. Salehi, and M. Salehi, "The identification of Cryptosporidium species in Isfahan, Iran by PCR-RFLP analysis of the 18S rRNA gene," Molecular Biology, vol. 41, no. 5, pp. 851-856, 2007.

[11] M. Pirestani, J. Sadraei, A. Dalimi Asl, M. Zavvar, and H. Vaeznia, "Molecular characterization of Cryptosporidium isolates from human and bovine using 18s rRNA gene in Shahriar county of Tehran, Iran," Parasitology Research, vol. 103, no. 2, pp. 467-472, 2008.

[12] B. M. Ghalehbin, M. Arzanlou, E. Fallah, A. H. Kazemi, and M. Asgharzadeh, "Molecular identification of Cryptosporidium sp. in the cattle stool samples in Ardabil city, Northwestern Iran," Journal of Animal and Veterinary Advances, vol. 7, no. 3, pp. 246250, 2008.

[13] A. Keshavarz, A. Haghighi, A. Athari, B. Kazemi, A. Abadi, and E. N. Mojarad, "Prevalence and molecular characterization of bovine Cryptosporidium in Qazvin province, Iran," Veterinary Parasitology, vol. 160, no. 3-4, pp. 316-318, 2009.

[14] A. Hassanpour, "Prevalence of cryptosporidiosis in calves and humans to be in contact them in tabriz area in Iran," International Journal of Infectious Diseases, vol. 12, no. 1, article 126, 2008.

[15] A. P. Sturdee, A. T. Bodley-Tickell, A. Archer, and R. M. Chalmers, "Long-term study of Cryptosporidium prevalence on a lowland farm in the United Kingdom," Veterinary Parasitology, vol. 116, no. 2, pp. 97-113, 2003.

[16] M. E. Olson, R. M. O’Handley, B. J. Ralston, T. A. McAllister, and R. C. A. Thompson, "Update on Cryptosporidium and Giardia infections in cattle," Trends in Parasitology, vol. 20, no. 4, pp. 185-191, 2004.

[17] M. Kváč, M. Kouba, and J. Vítovec, "Age-related and housingdependence of Cryptosporidium infection of calves from dairy and beef herds in South Bohemia, Czech Republic," Veterinary Parasitology, vol. 137, no. 3-4, pp. 202-209, 2006.
[18] R. B. Langkjær, H. Vigre, H. L. Enemark, and C. Maddox-Hyttel, "Molecular and phylogenetic characterization of Cryptosporidium and Giardia from pigs and cattle in Denmark," Parasitology, vol. 134, no. 3, pp. 339-350, 2007.

[19] R. E. C. Huetink, J. W. B. Van der Giessen, J. P. T. M. Noordhuizen, and H. W. Ploeger, "Epidemiology of Cryptosporidium spp. and Giardia duodenalis on a dairy farm," Veterinary Parasitology, vol. 102, no. 1-2, pp. 53-67, 2001.

[20] L. A. Trotz-Williams, S. Wayne Martin, K. E. Leslie, T. Duffield, D. V. Nydam, and A. S. Peregrine, "Calf-level risk factors for neonatal diarrhea and shedding of Cryptosporidium parvum in Ontario dairy calves," Preventive Veterinary Medicine, vol. 82, no. 1-2, pp. 12-28, 2007.

[21] Y. Feng, Y. Ortega, G. He et al., "Wide geographic distribution of Cryptosporidium bovis and the deer-like genotype in bovines," Veterinary Parasitology, vol. 144, no. 1-2, pp. 1-9, 2007.

[22] T. Geurden, D. Berkvens, C. Martens, S. Casaert, J. Vercruysse, and E. Claerebout, "Molecular epidemiology with subtype analysis of Cryptosporidium in calves in Belgium," Parasitology, vol. 134, no. 14, pp. 1981-1987, 2007.

[23] D. C. Feltus, C. W. Giddings, M. L. Khaitsa, and J. M. McEvoy, "High prevalence of Cryptosporidium bovis and the deer-like genotype in calves compared to mature cows in beef cow-calf operations," Veterinary Parasitology, vol. 151, no. 2-4, pp. 191$195,2008$.

[24] H. P. Thompson, J. S. G. Dooley, J. Kenny et al., "Genotypes and subtypes of Cryptosporidium spp. in neonatal calves in Northern Ireland," Parasitology Research, vol. 100, no. 3, pp. 619-624, 2007.

[25] M. Santín, J. M. Trout, and R. Fayer, "A longitudinal study of cryptosporidiosis in dairy cattle from birth to 2 years of age," Veterinary Parasitology, vol. 155, no. 1-2, pp. 15-23, 2008.

[26] N. A. Halim, J. Plutzer, M. A. Bakheit, and P. Karanis, "First report of Cryptosporidium deer-like genotype in Malaysian cattle," Veterinary Parasitology, vol. 152, no. 3-4, pp. 325-329, 2008.

[27] E. J. Brook, C. Anthony Hart, N. P. French, and R. M. Christley, "Molecular epidemiology of Cryptosporidium subtypes in cattle in England," Veterinary Journal, vol. 179, no. 3, pp. 378-382, 2009.

[28] L. Xiao, "Molecular epidemiology of cryptosporidiosis: an update," Experimental Parasitology, vol. 124, no. 1, pp. 80-89, 2010.

[29] R. M. Chalmers, K. Elwin, A. L. Thomas, E. C. Guy, and B. Mason, "Long-term Cryptosporidium typing reveals the aetiology and species-specific epidemiology of human cryptosporidiosis in England and Wales, 2000 to 2003," Euro Surveillance, vol. 14, no. 2, pp. 1-9, 2009.

[30] A. Zintl, A. F. Proctor, C. Read et al., "The prevalence of Cryptosporidium species and subtypes in human faecal samples in Ireland," Epidemiology and Infection, vol. 137, no. 2, pp. 270277, 2009.

[31] A. R. Meamar, K. Guyot, G. Certad et al., "Molecular characterization of Cryptosporidium isolates from humans and animals in Iran," Applied and Environmental Microbiology, vol. 73, no. 3, pp. 1033-1035, 2007.

[32] F. A. Al-Brikan, H. S. Salem, N. Beeching, and N. Hilal, "Multilocus genetic analysis of Cryptosporidium isolates from Saudi Arabia," Journal of the Egyptian Society of Parasitology, vol. 38, no. 2, pp. 645-658, 2008.

[33] I. M. Sulaiman, P. R. Hira, L. Zhou et al., "Unique endemicity of cryptosporidiosis in children in Kuwait," Journal of Clinical Microbiology, vol. 43, no. 6, pp. 2805-2809, 2005. 
[34] T. D. Morse, R. A. B. Nichols, A. M. Grimason, B. M. Campbell, K. C. Tembo, and H. V. Smith, "Incidence of cryptosporidiosis species in paediatric patients in Malawi," Epidemiology and Infection, vol. 135, no. 8, pp. 1307-1315, 2007.

[35] A. J. U. D. S. Araújo, H. Y. Kanamura, M. E. De Almeida, A. H. D. S. Gomes, T. H. L. Pinto, and A. J. Da Silva, "Genotypic identification of Cryptosporidium spp. isolated from HIV-infected patients and immunocompetent children of São Paulo, Brazil," Revista do Instituto de Medicina Tropical de Sao Paulo, vol. 50, no. 3, pp. 139-143, 2008.

[36] A. R. Jex, A. Pangasa, B. E. Campbell et al., "Classification of Cryptosporidium species from patients with sporadic cryptosporidiosis by use of sequence-based multilocus analysis following mutation scanning," Journal of Clinical Microbiology, vol. 46, no. 7, pp. 2252-2262, 2008.

[37] J. Siwila, I. G. K. Phiri, J. Vercruysse et al., "Asymptomatic cryptosporidiosis in Zambian dairy farm workers and their household members," Transactions of the Royal Society of Tropical Medicine and Hygiene, vol. 101, no. 7, pp. 733-734, 2007.

[38] P. R. Wielinga, A. de Vries, T. H. van der Goot et al., "Molecular epidemiology of Cryptosporidium in humans and cattle in The Netherlands," International Journal for Parasitology, vol. 38, no. 7, pp. 809-817, 2008.

[39] B. Robertson, M. I. Sinclair, A. B. Forbes et al., "Case-control studies of sporadic crytosporidiosis in Melbourne and Adelaide, Australia," Epidemiology and Infection, vol. 128, no. 3, pp. 419431, 2002.

[40] S. L. Roy, S. M. DeLong, S. A. Stenzel et al., "Risk factors for sporadic cryptosporidiosis among immunocompetent persons in the United States from 1999 to 2001," Journal of Clinical Microbiology, vol. 42, no. 7, pp. 2944-2951, 2004.

[41] P. R. Hunter, S. Hughes, S. Woodhouse et al., "Sporadic cryptosporidiosis case-control study with genotyping," Emerging Infectious Diseases, vol. 10, no. 7, pp. 1241-1249, 2004.

[42] L. Robertson, B. Gjerde, T. Forberg, G. Haugejorden, and C. Kielland, "A small outbreak of human cryptosporidiosis associated with calves at a dairy farm in Norway," Scandinavian Journal of Infectious Diseases, vol. 38, no. 9, pp. 810-813, 2006.

[43] G. Preiser, L. Preiser, and L. Madeo, "An outbreak of cryptosporidiosis among veterinary science students who work with calves," Journal of American College Health, vol. 51, no. 5, pp. 213-215, 2003.

[44] K. M. Kiang, J. M. Scheftel, F. T. Leano et al., "Recurrent outbreaks of cryptosporidiosis associated with calves among students at an educational farm programme, Minnesota, 2003," Epidemiology and Infection, vol. 134, no. 4, pp. 878-886, 2006.

[45] F. Ondriska, I. Vrabcová, S. Brind'áková et al., “The first reported cases of human cryptosporidiosis caused by Cryptosporidium hominis in Slovak Republic," Folia Microbiologica, vol. 58, no. 1, pp. 69-73, 2013.

[46] J. Yakoob, Z. Abbas, M. A. Beg et al., "Prevalences of Giardia lamblia and Cryptosporidium parvum infection in adults presenting with chronic diarrhoea," Annals of Tropical Medicine and Parasitology, vol. 104, no. 6, pp. 505-510, 2010.

[47] R. Jafari, A. H. Maghsood, and M. Fallah, "Prevalence of cryptosporidium infection among livestock and humans in contact with livestock in hamadan district, Iran, 2012," Journal of Research in Health Sciences, vol. 13, no. 1, pp. 86-89, 2012.

[48] M. Izadi, N. Jonaidi-Jafari, A. Saburi, H. Eyni, M. R. Rezaiemanesh, and R. Ranjbar, "Prevalence, molecular characteristics and risk factors for cryptosporidiosis among Iranian immunocompromised patients," Microbiology and Immunology, vol. 56, no. 12, pp. 836-842, 2012.

[49] F. F. Gil, M. J. Barros, N. A. Macedo et al., "Prevalence of intestinal parasitism and associated symptomatology among hemodialysis patients," Revista do Instituto de Medicina Tropical de São Paulo, vol. 55, no. 2, pp. 69-74, 2013. 


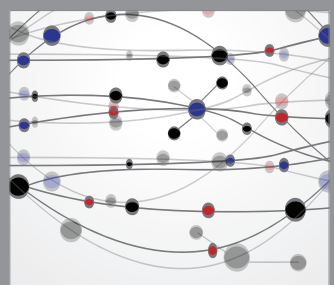

The Scientific World Journal
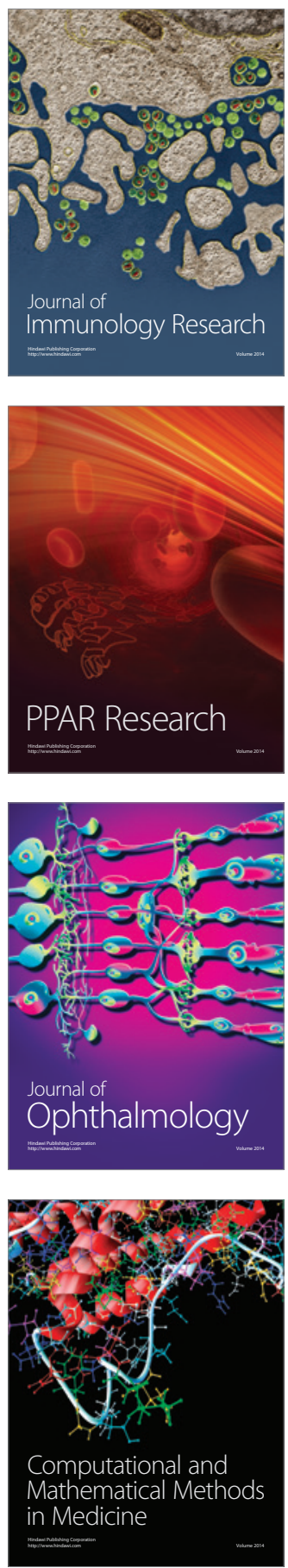

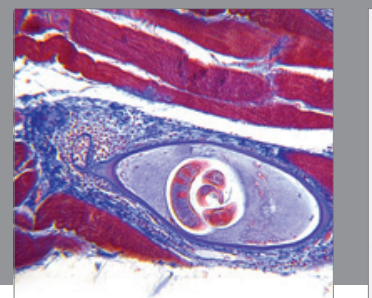

Gastroenterology

Research and Practice
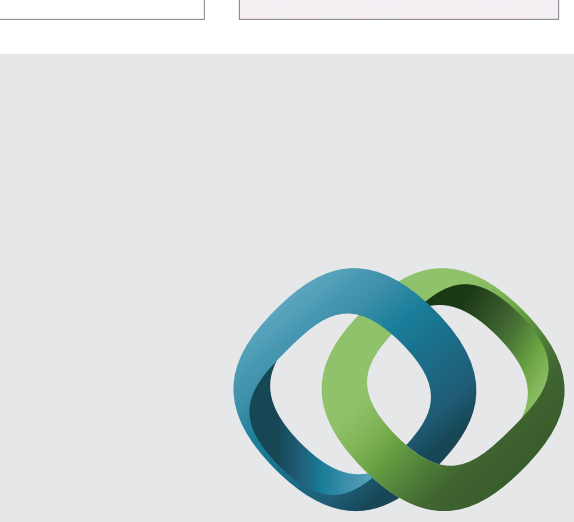

\section{Hindawi}

Submit your manuscripts at

http://www.hindawi.com
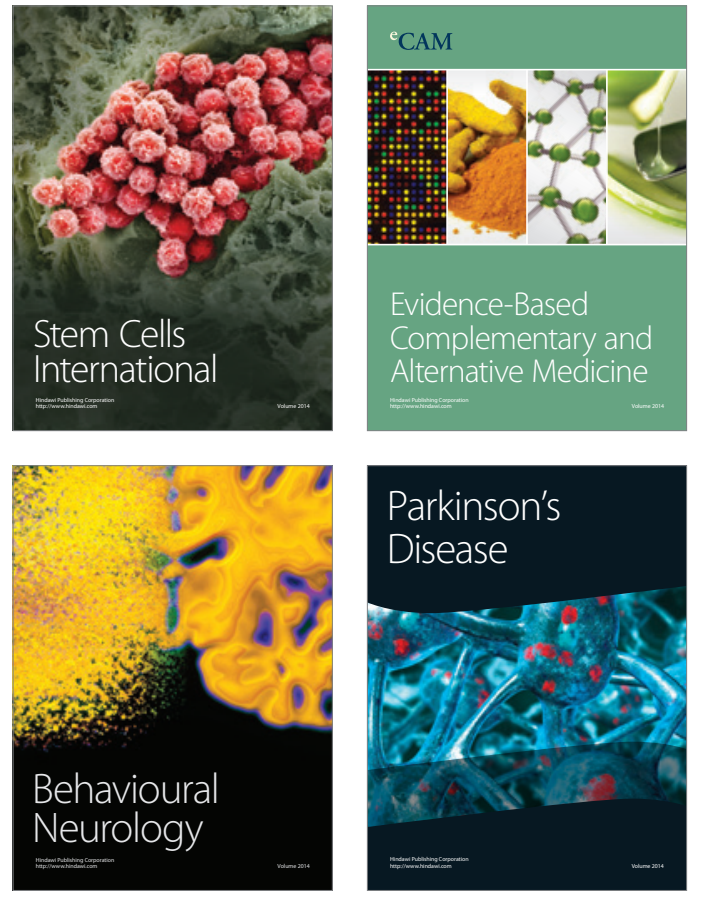
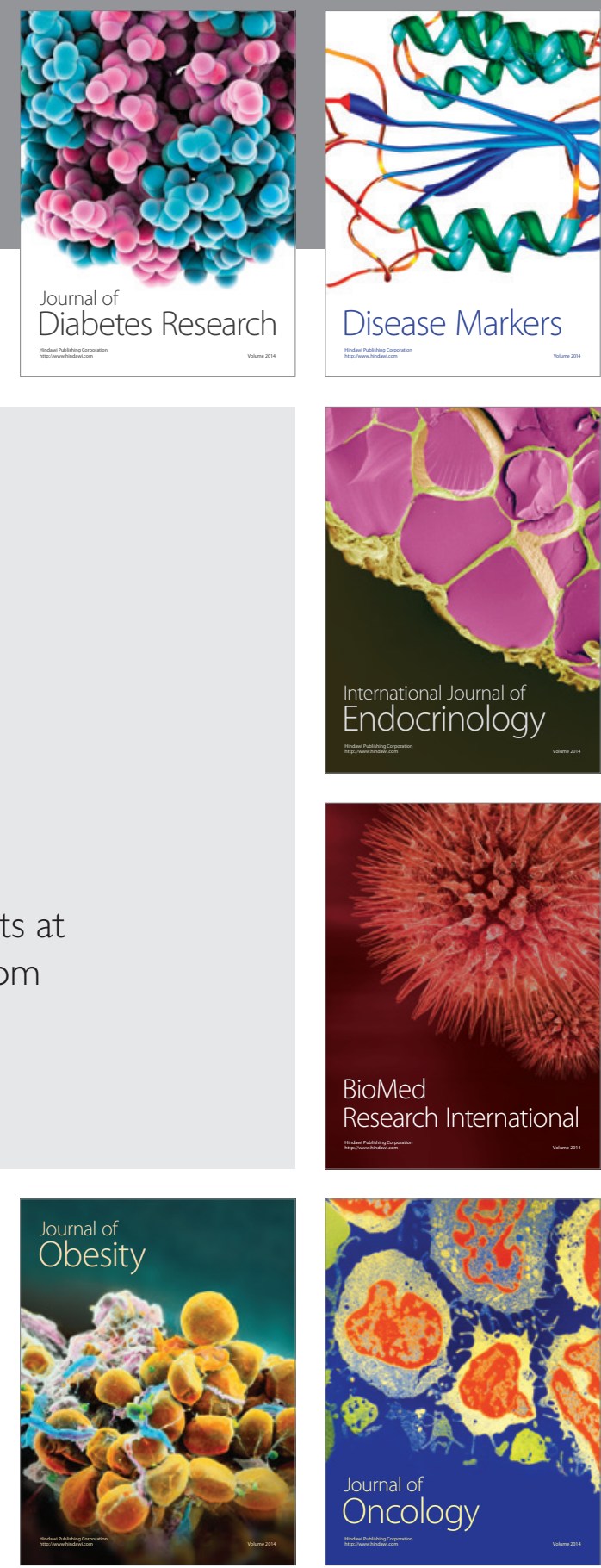

Disease Markers
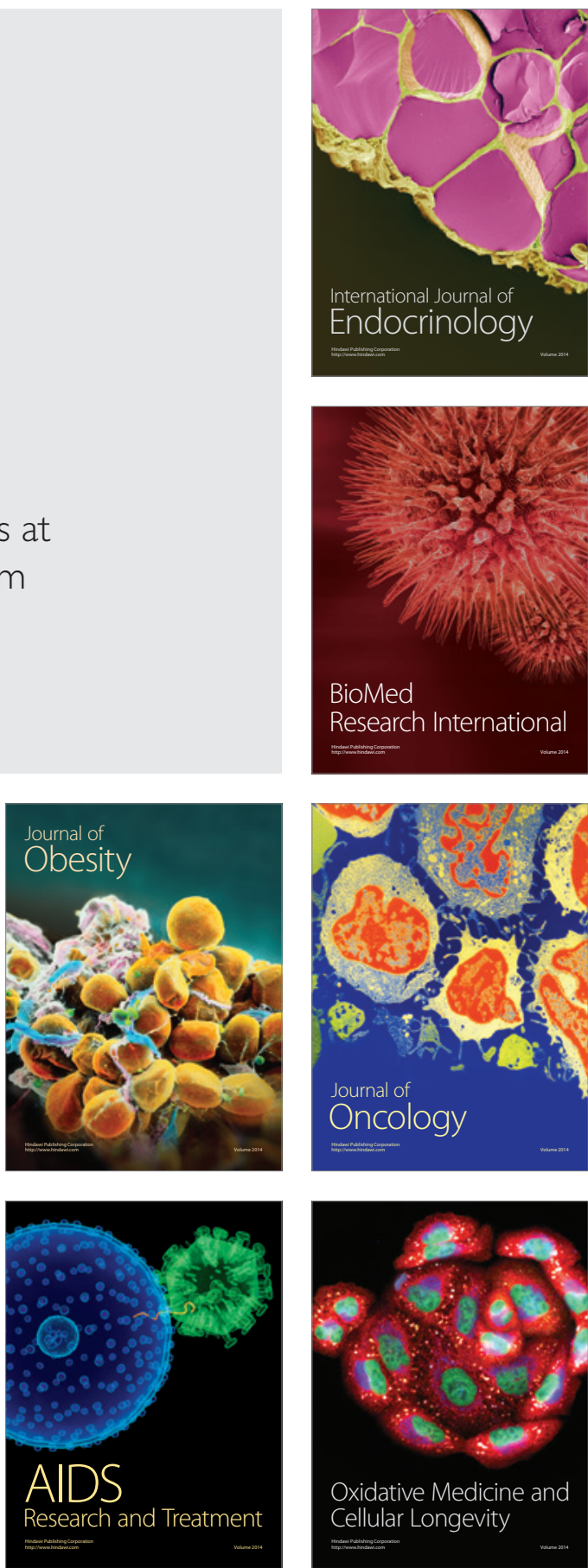